\title{
Beyond Cash Bail: Public Health, Risk Assessment, and California Senate Bill 10
}

\section{Zoe Guttman' ${ }^{1}$, Yuki Hebner², Kanon Mori³ ${ }^{3}$ Jonathan Balk}

1University of California, Los Angeles, Neuroscience Interdepartmental Program, 760 Westwood Plaza, Los

Angeles, CA

${ }^{2}$ University of California, Los Angeles, Molecular Biology Interdepartmental Program, 635 Charles E. Young

Dr S, Los Angeles, CA

${ }^{3}$ University of California, Los Angeles, Department of Molecular, Cellular, and Developmental Biology, 610

Charles E Young Dr S, Los Angeles, CA

${ }^{4}$ University of California, Los Angeles, Department of Mechanical and Aerospace Engineering, 420 Westwood

Plaza, Los Angeles, CA

http://doi.org/10.38126/JSPG170107

Corresponding Author: zoeguttman@gmail.com

Keywords: science policy; mental health; public health; risk assessment; cash bail; pretrial detention;

California

Executive Summary: The detrimental effects of incarceration on physical and mental health are widely acknowledged. However, $76 \%$ of the United States jail population is awaiting trial without having been convicted of a crime (Sawyer and Wagner 2020). This is driven by the monetary bail system, which the state of California moved to abolish by passing the 2018 California Money Bail Reform Act (Senate Bill 10, hereafter SB 10). SB 10 proposes the use of algorithmically driven risk assessment tools to determine pretrial release. However, actuarial risk assessments are not calibrated to California's diverse demography and are insufficient to determine which defendants pose flight or public safety risks. SB 10 is predicted to perpetuate similar socioeconomic and racial disparities as the current system, while failing to decrease pretrial detention. We recommend opposing SB 10 in favor of pretrial release for most misdemeanor and nonviolent defendants. The funding currently allocated for pretrial detainment should be redirected toward evidence-based and restorative pretrial supervision practices through the enactment of new bail-reform legislation by the state of California. Increasing the use of diversion programs, which redirect defendants to the appropriate mental health or substance abuse programs, also presents opportunities to restore treatment to the jurisdiction of public health rather than criminal justice. Transitioning from a reliance on pretrial detention to pretrial services will mitigate the collateral effects of incarceration while improving public health, public safety, and substantially reducing the cost of incarceration.

\section{Statement of issue}

While criminal law in the United States is based on a presumption of innocence and reserves pretrial detention for unmanageable flight or public safety risks (Jones 2013), the pretrial incarceration rate constitutes over $95 \%$ of the growth in jail population over the last twenty years (Sawyer and Wagner 2020). This is a direct consequence of the monetary bail system, which incarcerates those awaiting trial if unable to meet a financial requirement. This is especially prevalent in
California, which has higher bail costs (five times the country's median in 2009 (State Court Processing Statistics 2009)) and higher rates of pretrial detention in its urban counties compared to that of other states (Tafoya 2015; Board of State and Community Corrections 2019).

Cash Bail can facilitate the release of highrisk/violent defendants (Laura and John Arnold Foundation 2013) and is socioeconomically and racially discriminatory (Gelbach and Bushway 
2011; Demuth and Steffensmeier 2004; Jones 2013). People unable to afford bail fall in the poorest third of society and many of those incarcerated fall below the poverty line (Rabuy and Kopf 2016). In California, bail amounts are higher for Black men by $35 \%$ and Hispanic men by $19 \%$ compared to white men accused of similar crimes (Gelbach and Bushway 2011). Low-income defendants are also disproportionately exposed to profitable exploitation by the commercial bail industry (Appleman 2016; Holland-Stergar et al. 2017; Rabuy and Kopf 2016) (i.e., nonrefundable premiums, interest rates, fines), which has minimal oversight and is not subject to the constitutional restrictions that limit state actions (Johnson and Stevens 2013; Johnson and Warchol 2003).

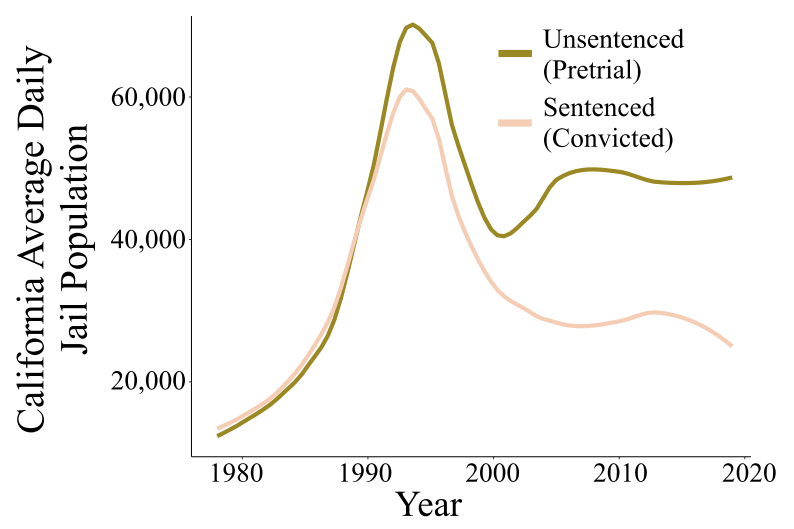

Figure 1: Author calculations from Board of State and Community Corrections (Board of State and Community Corrections 2019) and Bureau of Justice Statistics (State Court Processing Statistics 2009) data.

Pretrial detention detracts from public health and public safety. Imprisonment for as few as three days increases the chance of conviction and future arrest for different crimes (Lowenkamp, VanNostrand, and Holsinger 2013a), especially in individuals suffering from mental illnesses and addictions (Kouyoumdjian et al. 2015; Deitch, Koutsenok, and Ruiz 2000; Prendergast et al. 2004; Caspar and Joukov 2020; Leutwyler, Hubbard, and Zahnd 2017). Detainees awaiting trial face damaging consequences, including loss of employment, schooling, housing, custody of their children, and access to medical care (Rabuy and Kopf 2016; Appleman 2016; Holland-Stergar et al. 2017; Comfort 2016; Stevenson and Mayson 2017). For example, the Medicaid Inmate Exclusion Policy lacks automated reinstatement of Medicaid following release and creates gaps in healthcare coverage that amplify health, social, and financial burdens associated with recidivism (Albertson et al. 2020). Studies suggest that local jails, where most pretrial detainees are held, cause greater negative health outcomes than prisons because they are typically less equipped to provide medical services (Toman, Cochran, and Cochran 2018; Yi, Turney, and Wildeman 2017; Caspar and Joukov 2020). These issues are compounded by the COVID-19 pandemic, as the rate of COVID-19 cases in jails is $5.5 \mathrm{x}$ higher than the U.S. population (Saloner et al. 2020).

Pretrial detention also costs California nearly $\$ 30$ billion per year (Amatya et al. 2017) and increases the severity of sentencing and the likelihood of incarceration, recidivism, and conviction (Dobbie, Goldin, and Yang 2018; Gupta, Hansman, and Frenchman 2016; Lowenkamp, VanNostrand, and Holsinger 2013b; Phillips 2012; Ottone and Scott-Hayward 2018; Heaton, Mayson, and Stevenson 2017; Stevenson 2018b; Lowenkamp, VanNostrand, and Holsinger 2013a; Lum, Ma, and Baiocchi 2017). A detainee is 3-4 times more likely to be sentenced than someone released on bail for the same crime (Lowenkamp, VanNostrand, and Holsinger 2013b), partly because of incentivization to take plea deals to negotiate release (Dobbie, Goldin, and Yang 2018; Ottone and Scott-Hayward 2018; Stevenson 2018b; Heaton, Mayson, and Stevenson 2017). California spent $\$ 37.5$ million in just six counties from 2014-2015 detaining people whose cases were never filed or were dismissed (Not in it for Justice: How California's Pretrial Detention and Bail System Unfairly Punishes Poor People 2017).

Meanwhile, evidence suggests that increasing pretrial release does not increase court absences or criminal activity while awaiting trial (Pretrial Justice Institute 2009; Ouss and Stevenson 2020; Grant 2019; Office of the Chief Judge 2019; Philadelphia District Attorney's Office 2019; Neal 2019). While the system was designed to balance public safety with the health and equity of those accused, the high rate of pretrial detention has created systemic inefficiencies.

Moreover, support for general bail reform has been growing. A 2018 national survey of 1,400 registered voters showed overwhelming support 
for pretrial reform, including increased use of citations instead of arrest (76\%) and pretrial services for mental health (89\%) and substance use (77\%) issues(Pretrial Justice Institute 2018). The monetary bail system has been challenged on local, state, and federal levels, with bipartisan bills calling for reforms (Pretrial Integrity and Safety Act 2017; No Money Bail Act 2017). Additionally, legal actions in many state courts have maintained that unaffordable bail is unconstitutional (ScottHayward and Ottone 2018; Sparks 2019; Morgan 2019).

Criminal justice reforms should rely on evidencebased practices that do not compromise public safety, such as greater reliance on pretrial release and restorative diversion and supervision services.

\section{Policy options}

\section{i. Option 1: Support SB 10 (Vote "Yes" to Proposition} 25)

SB 10 eliminates monetary bail and adopts "preventive detention" that uses actuarial risk assessment tools to classify defendants into low, medium, and high risk. Those of "low risk" can be immediately released. Otherwise, release versus detainment is determined by local standards and the discretion of judges, prosecutors, county boards of supervisors, and/or pretrial officials. While SB 10 was enacted in 2018, implementation of the legislation was suspended by a veto referendum (Referendum 1856) that will be on the November 2020 ballot as Proposition 25 .

\section{Advantages}

SB 10 would eliminate cash bail, a system contingent on financial capacity that is socioeconomically and racially discriminatory (Gelbach and Bushway 2011; Demuth and Steffensmeier 2004; Jones 2013). Even low bail levels drive incarceration, as median bail remains larger than the savings of a typical American household (Liu, Nunn, and Shambaugh 2018). In California, a 31\% reduction in bail would only help $4 \%$ of offenders, and even a $90 \%$ decrease puts average bail at $\$ 5,000$, still unaffordable for many (Tafoya 2013). The commercial bail industry is especially harmful towards low-income defendants who can become forced into a cycle of poverty and incarceration (Appleman 2016;
Holland-Stergar et al. 2017; Rabuy and Kopf 2016; Johnson and Stevens 2013; Johnson and Warchol 2003). Additionally, this wealth-based system predictably discriminates based on race (Gelbach and Bushway 2011; Demuth and Steffensmeier 2004; Jones 2013). Court officials have broad discretion in decision-making and the likelihood of pretrial release and bail amount is alarmingly arbitrary across judges and locations (Ottone and Scott-Hayward 2018; Barry-Jester 2018; Sheriff's Justice Institute 2016; Hood and Schneider 2019). In theory, actuarial risk assessment tools are more objective and less subject to racial bias.

\section{Disadvantages}

Evidence suggests that replacing cash bail with actuarial risk assessment tools, as proposed by SB 10 , is insufficient to promote pretrial release and decrease incarceration and may maintain or increase incarceration rates (Stevenson and Doleac 2019; Stevenson 2018a; Stevenson and Slobogin 2018; Ouss and Stevenson 2020; Starr 2014; Dressel and Farid 2018). Arrests for violent crime while on pretrial release are rare and difficult to statistically predict (Hart and Cooke 2013). Actuarial risk assessments use tail risk models that have low explanatory/predictive power and trend towards overestimations (Angwin et al. 2016; Hart and Cooke 2013). They also have broad and imprecise definitions of risk (Barabas et al. 2019; Starr 2014; Gouldin 2018, 2016) (i.e., including minor offenses like missed court payments, conflating risk of danger and flight, and conflating risk of criminal behavior with risk of arrest). Even with the exclusion of race as a variable, their algorithms rely on demographic and socioeconomic variables highly correlated with race (Starr 2014; Angwin et al. 2016; Stevenson 2018a; Picard et al. 2019). The models also incorporate criminal history data that overrepresents criminality of non-white defendants, who are more likely to be arrested, prosecuted, and convicted for the same conduct as their white counterparts (Mitchell and Caudy 2015; Weaver, Papachristos, and Zanger-Tishler 2019; Rehavi and Starr 2014; Anwar, Bayer, and Hjalmarsson 2012; Abrams, Bertrand, and Mullainathan 2012; Angwin et al. 2016; Stevenson 2018a; Picard et al. 2019). Moreover, SB 10 does not require judicial adherence to such tools, nor 
does it specify which actuarial tool will be employed. Such tools are often proprietary and lack transparency (Barabas et al. 2019; Clayton 2018; Stevenson and Slobogin 2018). Thus, current risk assessment tools are unlikely to decrease pretrial incarceration; in many regions that have adopted such tools, rates of incarceration have either remained constant or have increased (Stevenson 2018a; Stevenson and Doleac 2019; Stevenson and Slobogin 2018; Ouss and Stevenson 2020; Starr 2014; Dressel and Farid 2018). Without lowering pretrial incarceration, a decrease in spending on incarceration is not anticipated.

\section{ii. Option 2: Oppose SB 10 (Vote "No" to Proposition 25) \\ Voting "No" to Proposition 25 will prevent SB 10 from being passed and result in no change to the current monetary bail system.}

\section{Advantages}

Analyses of SB 10 reveal that it is unlikely to decrease pretrial detention and will exacerbate racial inequalities perpetuated by the current cash bail system (Stevenson and Doleac 2019; Stevenson 2018a; Stevenson and Slobogin 2018; Ouss and Stevenson 2020; Starr 2014; Dressel and Farid 2018). An ineffective law can serve as a roadblock to reform by taking up limited resources, creating a false sense of progress, and delaying the introduction of reparative legislation. Racial and socioeconomic marginalization and oppression by the cash bail system would persist.

\section{Disadvantages}

Maintaining the current system is damaging to individuals, expensive, and dangerous to public safety and health. A large number of pretrial detainees face severe physical and mental health issues (Yi, Turney, and Wildeman 2017; Human Impact Partners 2020; Stevenson 2018b; Stevenson and Mayson 2017; Comfort 2016). These harms burden low-income and nonwhite individuals the most (Appleman 2016; HollandStergar et al. 2017; Rabuy and Kopf 2016; Gelbach and Bushway 2011; Demuth and Steffensmeier 2004; Jones 2013). Pretrial detainment is also expensive; in Santa Clara County, each person costs $\$ 15$ per day if released, as opposed to $\$ 204$ per day if detained (County of Santa Clara Bail and Release Work Group 2016).

Option 3: Oppose SB 10 (Vote "No" to Proposition 25) and introduce new legislation

A new bill should be introduced that shifts the focus from detainment to release for misdemeanor/nonviolent defendants. Prior to arraignment, law enforcement and pretrial officers can be given the discretion to release people through citations and diversion programs, which are effective (Ochoa et al. 2019) but underused (Holliday et al. 2020) in places like Los Angeles County. Diversion programs address individual needs like homelessness, addiction, and mental illness by redirecting defendants to the relevant medical and community-based professionals. After meeting court-specified requirements, charges may be dropped and jail time avoided. Decisions about pretrial detainment versus release should be modeled after successful bail reform in other states such as New Jersey (Shalom et al. 2016). Most misdemeanors/nonviolent defenders should be released, either on their own recognizance or in tandem with supervision and pretrial services.

Actuarial risk assessment tools should be designed to aid, not replace, judges in their decision making. These tools can be improved by the use of transparent and uncomplicated models (Zeng, Ustun, and Rudin 2017; Dressel and Farid 2018) and by excluding discriminatory variables that are unpredictive of recidivism, such as socioeconomic status of family of origin (Gendreau, Little, and Goggin 1996). Models can also be trained on local races/ethnicities to increase accuracy and equity (Gasek 2019; Clayton 2018; Mamalian 2011). Non-invasive supervision and restorative/community-oriented pretrial services, like counseling and skills training, can be provided by agencies independent from the court and probation departments (National Assosiation of Pretrial Services Agencies 2004).

\section{Advantages}

Increasing pretrial release does not result in more court absences, violent crimes, or arrests(Pretrial Justice Institute 2009; Ouss and Stevenson 2020; Grant 2019; Office of the Chief Judge 2019; Philadelphia District Attorney's Office 2019; Neal 2019). Reduced misdemeanor arrests and 
increased flexibility for pretrial officers to divert arrests will decrease the burden placed on judges and increases equity (Harris, Goss, and Gumbs 2019; Weaver, Papachristos, and Zanger-Tishler 2019). Diversion programs restore treatment of mental illness and substance abuse to medical professionals, reducing the burden on the criminal justice system and promoting behavioral change. Bail reforms with mandatory release on recognizance in other states have been largely successful (Grant 2019). Studies suggest that common interventions prioritizing discipline and surveillance are ineffective (MacKenzie and Farrington 2015; Bechtel et al. 2017), can elevate incarceration rates through technical violations (Turner, Petersilia, and Deschenes 1992; Hyatt and Barnes 2017), and cause financial strain (i.e., mandatory courses that impede employment, expensive ankle monitors) (Doyle, Bains, and Hopkins 2019).

The emphasis should be placed on restorative, community-based interventions shown to be effective and typically more cost-effective (MacKenzie and Farrington 2015; Bechtel et al. 2017; Barnes et al. 2010; County of Santa Clara Bail and Release Work Group 2016; Gasek 2019; Cooke et al. 2018). For example, behavioral nudges, such as text message reminders and transportation to court appearances, effectively and relatively inexpensively increase court appearances (Cooke et al. 2018; Rosenbaum et al. 2011; Schnacke, Jones, and Wilderman 2012; White 2006; Pretrial Justice Institute 2012). Improving pretrial services is projected to create thousands of new jobs and the cost is significantly outweighed by the billions of dollars California would save annually by decreasing pretrial detention (in 2014, an estimated $\$ 10$ billion with a pretrial detainment rate of $40 \%$, and $\$ 20$ billion at $10 \%$ )(Amatya et al. 2017).

\section{Disadvantages}

Such a bill is currently not in place and would take time to develop. Reform efforts could be harmed by a violent crime being committed by an individual awaiting trial.

\section{Policy recommendation}

We recommend Option 3: Oppose SB 10 (Vote "No" on Proposition 25) and introduce new legislation. Monetary bail is an ineffective and inefficient public safety measure, but there is converging evidence that SB 10 inadequately addresses the underlying issue of pretrial detention by relying too heavily on actuarial risk assessment tools. These tools are projected to perpetuate racial and socioeconomic discrimination (Angwin et al. 2016; Picard et al. 2019; Starr 2014; Stevenson and Doleac 2019; Stevenson 2018a; Stevenson and Slobogin 2018; Ouss and Stevenson 2020; Dressel and Farid 2018). For those accused of misdemeanor/nonviolent crimes, the standard should be mandatory pretrial release in conjunction with restorative, community-based interventions, already shown to be effective and cost-effective (MacKenzie and Farrington 2015; Bechtel et al. 2017; Barnes et al. 2010; County of Santa Clara Bail and Release Work Group 2016; Gasek 2019).

For instance, in California's Santa Clara County, which has shifted to community-sponsored release, defendants can choose community organizations like churches to run their pretrial services. 95\% of released defendants appear for court dates and only $1 \%$ are re-arrested while awaiting trial (County of Santa Clara Bail and Release Work Group 2016). These rates are comparable to those of other regions with bail reforms (Pretrial Justice Institute 2009; Ouss and Stevenson 2020; Grant 2019; Stevenson 2018a; Stevenson and Mayson 2017; Office of the Chief Judge 2019; Philadelphia District Attorney's Office 2019; Neal 2019).

We further recommend that policy emphasize longitudinal assessment, stakeholder input, and transparency. Data should be regularly collected along the pretrial pipeline for independent assessment. Public reporting mechanisms exist that compare behavior to objective measures and ensure transparency (i.e., public report cards for surgeons [Kolstad 2013]). Investing in randomized control trials can clarify causal effects of pretrial release, supervision, and pretrial services (Greiner and Maréchal). Frequent reports from longitudinal analyses can also help garner public support. 
While most Americans believe mass incarceration to be a problem (American Civil Liberties Union 2017; Clarke 2018; Pretrial Justice Institute 2018), bail reform must address the fear that reducing the jail population threatens community safety. Effectively shifting pretrial standards requires public trust and support, and any strategy should highlight safety statistics from jurisdictions that have successfully implemented reforms without a significant rise in violent crimes or court absences (Pretrial Justice Institute 2009; Ouss and Stevenson 2020; Grant 2019; Stevenson 2018a;

\section{References}

Abrams, David S., Marianne Bertrand, and Sendhil Mullainathan. 2012. "Do judges vary in their treatment of race?" The Journal of Legal Studies 41 (2): 347-383. https://doi.org/10.1086/666006.

Albertson, Elaine Michelle, Christopher Scannell, Neda Ashtari, and Elizabeth Barnert. 2020.

"Eliminating gaps in medicaid coverage during reentry after incarceration." American Journal of Public Health 110 (3): 317-321. https://doi.org/10.2105/ajph.2019.305400

Amatya, Pranita, Shelby King, Shelby McNabb, and Heidi Schultheis. 2017. Bail Reform in California. UCLA Luskin School of Public Affairs.

https://university.pretrial.org/HigherLogic/Sy stem/DownloadDocumentFile.ashx?Document FileKey=835f283a-e9fc-9c56-28bb073a9bcb1dbf.

American Civil Liberties Union, November 16, 2017, "91\% of Americans support criminal justice reform, ACLU polling finds," https://www.aclu.org/press-releases/91percent-americans-support-criminal-justicereform-aclu-polling-finds.

Angwin, Julia, Jeff Larson, Surya Mattu, and Lauren Kirchner. 2016. Machine bias. (ProPublica). https://www.propublica.org/article/machinebias-risk-assessments-in-criminal-sentencing.

Anwar, Shamena, Patrick Bayer, and Randi Hjalmarsson. 2012. "The impact of jury race in criminal trials." The Quarterly Journal of Economics 127 (2): 1017-1055. https://doi.org/10.1093/qje/qjs014.

Appleman, Laura. 2016. "Nickel and Dimed into Incarceration: Cash-Register Justice in the Criminal System." Boston College Law Review 57: 1483.

https://lawdigitalcommons.bc.edu/bclr/vol57 Liss $5 / 2$.
Stevenson and Mayson 2017; Office of the Chief Judge 2019; Philadelphia District Attorney's Office 2019; Neal 2019). Transparency and education for the public and relevant actors, including judges and probation officials, may help ease the transition away from detention, build trust in justice and law enforcement agencies, and result in better public health and justice outcomes. Shifting towards release instead of detainment is the only option that ensures equitable treatment and mitigates the health detriments of detainment.

Barabas, Chelsea, Ruha Benjamin, John Bowers, Meredith Broussard, Joy Buolamwini, Sasha Constanza-Chock, Kate Crawford, Karthik Dinakar, Colin Doyle, Timnit Gebru, Bernard E. Harcourt, Stefan Helreich, Brook Hopkins, Joichi Ito, Martha Minow, Cathy O'Neil, Rodrigo Ochigame, Heather Paxson, Venerable Tenzin Priyadarshi, Rashida Richardson, Bruce Schneier, Jason Schultz, Jeffrey Selbin, Vincent M. Southerland, Jordi Weinstock, Jonathan Zittrain, and Ethan Zuckerman. 2019. Technical Flaws of Pretrial Risk Assessments Raise Grave Concerns. https://pbtx.com/files/2019/12/TechnicalFla wsOfPretrial_ML_site.pdf.

Barnes, Geoffrey C, Lindsay Ahlman, Charlotte Gill, Lawrence W Sherman, Ellen Kurtz, and Robert Malvestuto. 2010. "Low-intensity community supervision for low-risk offenders: a randomized, controlled trial." Journal of Experimental Criminology 6 (2): 159-189. https://doi.org/10.1007/s11292-010-9094-4.

Barry-Jester, Anna Maria. 2018. You've been arrested. Will you get bail? Can you pay it? It may all depend on your judge. FiveThirtyEight. https://fivethirtyeight.com/features/youvebeen-arrested-will-you-get-bail-can-you-payit-it-may-all-depend-on-your-judge/.

Bechtel, Kristin, Alexander M Holsinger, Christopher T Lowenkamp, and Madeline J Warren. 2017. "A meta-analytic review of pretrial research: Risk assessment, bond type, and interventions." American Journal of Criminal Justice 42 (2): 443-467. https://doi.org/10.1007/s12103016-9367-1.

Board of State and Community Corrections. 2019. Jail Profile Survey. (Sacramento, California). http://www.bscc.ca.gov/s fsojailprofilesurvey L. 
Caspar, Samantha M., and Artem M. Joukov. 2020. "Mental Health and the Constitution: How Incarcerating the Mentally Ill Might Pave the Way to Treatment." Nevada Law Journal 20 (2): 6. https://scholars.law.unlv.edu/nlj/vol20/iss2/ $\underline{6}$.

Clarke, Matthew. November 2018. Polls Show People Favor Rehabilitation over Incarceration. (Prison Legal News). https://www.prisonlegalnews.org/news/2018 Lnov/6/polls-show-people-favorrehabilitation-over-incarceration/.

Clayton, Jeffrey J. 2018. "Detention, Release From Jail, and Computerized Bail Justice in California: Is it 1984 All Over Again? What Can California Learn From the Last 30 Years of Bail Reform?" UCLA Criminal Justice Law Review 2 (1). https://escholarship.org/uc/item/6p31t6hv.

Comfort, Megan. 2016. "A Twenty-Hour-a-Day Job: The Impact of Frequent Low-Level Criminal Justice Involvement on Family Life." The Annals of the American Academy of Political and Social Science 665 (1): 63-79. https://doi.org/10.1177/0002716215625038.

Cooke, Brice, Binta Zahra Diop, Alissa Fishbane, Jonathan Hayes, Aurelie Ouss, and Anuj Shah. 2018. Using behavioral science to improve criminal justice outcomes. University of Chicago Crime Lab Report.

https://www.courthousenews.com/wpcontent/uploads/2018/01/crim-justreport.pdf.

County of Santa Clara Bail and Release Work Group. 2016. Final Consensus Report on Optimal Pretrial Justice.

https://www.sccgov.org/sites/ceo/Document s/final-consensus-report-on-optimal-pretrialjustice.pdf.

Deitch, David, Igor Koutsenok, and Amanda Ruiz. 2000. "The Relationship Between Crime and Drugs: What We Have Learned in Recent Decades." Journal of Psychoactive Drugs 32 (4): 391-397. https://doi.org/10.1080/02791072.2000.104 $\underline{00241 .}$.

Demuth, Stephen, and Darrell Steffensmeier. 2004. "The impact of gender and race-ethnicity in the pretrial release process." Social Problems 51 (2): 222-242.

https://doi.org/10.1525/sp.2004.51.2.222.

Dobbie, Will, Jacob Goldin, and Crystal S. Yang. 2018.

"The effects of pretrial detention on conviction, future crime, and employment: Evidence from randomly assigned judges." American

Economic Review 108 (2): 201-40. https://doi.org/10.1257/aer.20161503.
Doyle, Colin, Chiraag Bains, and Brook Hopkins. 2019.

Bail reform: A guide for state and local policymakers. Criminal Justice Policy Program, Harvard Law School.

http://cjpp.law.harvard.edu/assets/BailRefor m WEB.pdf.

Dressel, Julia, and Hany Farid. 2018. "The accuracy, fairness, and limits of predicting recidivism." Science Advances 4 (1). https://doi.org/10.1126/sciadv.aao5580.

Gasek, Jade. 2019. "Community First: Why California's Elimination of Cash Bail May Have Missed the Mark." University of the Pacific McGeorge Law Review 51: 1.

https://www.mcgeorge.edu/documents/Publi cations/gasek-tuoplr-511.pdf.

Gelbach, Jonah B., and Shawn D. Bushway. 2011. "Testing for Racial Discrimination in Bail Setting Using Nonparametric Estimation of a Parametric Model." Unpublished working paper. http://dx.doi.org/10.2139/ssrn.1990324.

Gendreau, Paul, Tracy Little, and Claire Goggin. 1996. "A meta-analysis of the predictors of adult offender recidivism: What works!" Criminology 34 (4): 575-608. https://doi.org/10.1111/j.17459125.1996.tb01220.x

Gouldin, Lauryn P. 2016. "Disentangling flight risk from dangerousness." BYU Law Review: 837. https://digitalcommons.law.byu.edu/lawrevie $\mathrm{w} /$ vol2016/iss $3 / 5 /$.

Gouldin, Lauryn P. 2018. "Defining flight risk." University of Chicago Law Review 85: 677. https://chicagounbound.uchicago.edu/uclrev/ vol85/iss $3 / 3$.

Grant, Glenn A. 2019. Report to the Governor and the Legislature. New Jersey Judiciary, Administrative Office of the Courts (New Jersey). https://www.njcourts.gov/courts/assets/crim inal/2018cjrannual.pdf.

Greiner, Jim, and Michel Maréchal. Decriminalizing the Poor - The Effects of Abolishing Cash Bail. NOMIS Research Project. https://nomisfoundation.ch/researchprojects/decriminalizing-the-poor-the-effectsof-abolishing-cash-bail/.

Gupta, Arpit, Christopher Hansman, and Ethan Frenchman. 2016. "The heavy costs of high bail: Evidence from judge randomization." The Journal of Legal Studies 45 (2): 471-505. https://doi.org/10.2139/ssrn.2774453. 
Harris, Heather, Justin Goss, and Alexandria Gumbs. December 2019. Pretrial Risk Assessment in California. Public Policy Institute of California. https://www.ppic.org/wpcontent/uploads/pretrial-risk-assessment-incalifornia.pdf.

Hart, Stephen D., and David J. Cooke. 2013. "Another look at the (Im-) precision of individual risk estimates made using actuarial risk assessment instruments." Behavioral Sciences \& The Law 31 (1): 81-102. https://doi.org/10.1002/bsl.2049.

Heaton, Paul, Sandra Mayson, and Megan Stevenson. 2017. "The downstream consequences of misdemeanor pretrial detention." Stanford Law Review 69: 711.

https://digitalcommons.law.uga.edu/fac artch op/1148.

Holland-Stergar, Brianne, Carolyn Barden, Alicia Brush, Rachel Clark, Shelby King, Jessica Cobb, and Neelum Arya. 2017. The Devil in the Details: Bail Contracts in California. UCLA School of Law Criminal Justice Reform Clinic. https://static.prisonpolicy.org/scans/UCLA D evil\%20 in the Details.pdf.

Holliday, Stephanie Brooks, Nicholas M Pace, Neil Gowensmith, Ira Packer, Daniel Murrie, Alicia Virani, Bing Han, and Sarah B Hunter. 2020. Los Angeles County Jails Could Divert More Individuals to Community-Based Mental Health Services. RAND Corporation. https://www.rand.org/content/dam/rand/pu bs/research briefs/RB10100/RB10111/RAND RB10111.pdf.

Hood, Katherine, and Daniel Schneider. 2019. "Bail and Pretrial Detention: Contours and Causes of Temporal and County Variation." The Russell Sage Foundation Journal of the Social Sciences 5 (1): 126-149.

https://doi.org/10.7758/rsf.2019.5.1.06.

Human Impact Partners. 2020. Liberating Our Health: Ending the Harms of Pretrial Incarceration and Money Bail. (Oakland, CA).

https://humanimpact.org/wpcontent/uploads/2020/02/HIP HealthNotBail NationalReport 2020.02 reduced.pdf.

Hyatt, Jordan M., and Geoffrey C. Barnes. 2017. "An experimental evaluation of the impact of intensive supervision on the recidivism of high-risk probationers." Crime \& Delinquency 63 (1): 3-38. https://doi.org/10.1177/0011128714555757.

Johnson, Brian R., and Ruth S. Stevens. 2013. "The regulation and control of bail recovery agents: An exploratory study." Criminal Justice Review 38 (2): 190-206. https://doi.org/10.1177/0734016812473823.
Johnson, Brian R., and Greg L. Warchol. 2003. "Bail agents and bounty hunters: Adversaries or allies of the justice system?" American Journal of Criminal Justice 27 (2): 145-165. https://doi.org/10.1007/BF02885691.

Jones, Cynthia E. 2013. "Give us free: Addressing racial disparities in bail determinations." Articles in Law Reviews \& Other Academic Journals 16: 919. https://digitalcommons.wcl.american.edu/facs ch lawrev/917.

Kolstad, Jonathan T. 2013. "Information and quality when motivation is intrinsic: Evidence from surgeon report cards." American Economic Review 103 (7): 2875-2910. https://doi.org/10.1257/aer.103.7.2875.

Kouyoumdjian, Fiona G., Kathryn E. McIsaac, Jessica Liauw, Samantha Green, Fareen Karachiwalla, Winnie Siu, Katie Burkholder, Ingrid Binswanger, Lori Kiefer, Stuart A. Kinner, Mo Korchinski, Flora I. Matheson, Pam Young, and Stephen W. Hwang. 2015. "A systematic review of randomized controlled trials of interventions to improve the health of persons during imprisonment and in the year after release." Am J Public Health 105 (4): e13-33. https://doi.org/10.2105/ajph.2014.302498.

Laura and John Arnold Foundation. 2013. Developing a National Model for Pretrial Risk Assessment. https://cjcc.doj.wi.gov/sites/default/files/sub committee/LJAF-research-summary PSACourt 4 1.pdf.

Leutwyler, Heather, Erin Hubbard, and Elaine Zahnd. 2017. "Case management helps prevent criminal justice recidivism for people with serious mental illness." International Journal of Prisoner Health. https://doi.org/10.1108/IJPH06-2016-0021.

Liu, Patrick, Ryan Nunn, and Jay Shambaugh. 2018. The economics of bail and pretrial detention. The Hamilton Project and the Brookings Institution. https://www.hamiltonproject.org/assets/files /BailFineReform EA 121818 6PM.pdf.

Lowenkamp, Christopher T, Marie VanNostrand, and Alexander M Holsinger. 2013a. The hidden costs of pretrial detention. Laura and John Arnold Foundation. https://craftmediabucket.s3.amazonaws.com/ uploads/PDFs/LJAF Report hiddencosts FNL.pdf. 
Lowenkamp, Christopher T, Marie VanNostrand, and Alexander M Holsinger. 2013b. Investigating the impact of pretrial detention on sentencing outcomes. Laura and John Arnold Foundation. https://craftmediabucket.s3.amazonaws.com/ uploads/PDFs/LJAF Report statesentencing_FNL.pdf.

Lum, Kristian, Erwin Ma, and Mike Baiocchi. 2017. "The causal impact of bail on case outcomes for indigent defendants in New York City."

Observational Studies 3: 39-64.

https://obsstudies.org/wpcontent/uploads/2017/10/bellamy redux rep ort.pdf.

MacKenzie, Doris L., and David P. Farrington. 2015. "Preventing future offending of delinquents and offenders: what have we learned from experiments and meta-analyses?" Journal of Experimental Criminology 11 (4): 565-595. https://doi.org/10.1007/s11292-015-9244-9.

Mamalian, Cynthia A. March 2011. State of the science of pretrial risk assessment. Pretrial Justice Institute.

https://bja.ojp.gov/sites/g/files/xyckuh186/fi les/Publications/PII PretrialRiskAssessment.p df.

Mitchell, Ojmarrh, and Michael S Caudy. 2015.

"Examining racial disparities in drug arrests." Justice Quarterly 32 (2): 288-313. https://doi.org/10.1080/07418825.2012.761 $\underline{721 .}$.

Morgan, Clinton. 2019. "Bail Fail: The Issues of Money Bail for the Indigent." Available at SSRN. https://doi.org/10.2139/ssrn.3457895.

National Assosiation of Pretrial Services Agencies. 2004. Standards on Pretrial Release. https://info.nicic.gov/nicrp/system/files/naps a-standards-2004.pdf.

Neal, Malik. November 2019. A Window Into a Future Without Cash Bail: A Snapshot Report on Resolved Cases of The Philadelphia Bail Fund. Philadelphia Bail Fund. https://static1.squarespace.com/static/591a4 fd51b10e32fb50fbc73/t/5dcd8edde0f89960f8 414eaa/1573752550092/PBF Resolved Case FINALpdf.pdf.

115th Congress. 2017. No Money Bail Act.

Not in it for Justice: How California's Pretrial Detention and Bail System Unfairly Punishes Poor People. April 11 2017. Human Rights Watch. https://www.hrw.org/report/2017/04/11/no t-it-justice/how-californias-pretrial-detentionand-bail-system-unfairly.
Ochoa, Kristen, Oona Appel, Viet Nguyen, and Elizabeth Kim. 2019. "Decriminalization in action: lessons from the Los Angeles model." CNS Spectrums: 1-5. https://doi.org/10.1017/S109285291900156 1.

Office of the Chief Judge. May 2019. Bail Reform in Cook County: An Examination of General Order 18.8A and Bail in Felony Cases. Circuit Court of Cook County (Chicago, Illinois). http://www.cookcountycourt.org/Portals/0/S tatistics/Bail\%20Reform/Bail\%20Reform \%20 Report $\% 20$ FINAL $\% 20$ \%20\%20Published\%2005.9.19.pdf.

Ottone, Sarah, and Christine S Scott-Hayward. 2018. "Pretrial detention and the decision to impose bail in Southern California." Criminology, Criminal Justice, Law and Society 19: 24. https://ccjls.scholasticahq.com/article/3789pretrial-detention-and-the-decision-toimpose-bail-in-southern-california.

Ouss, Aurelie, and Megan T. Stevenson. 2020. "Bail, Jail, and Pretrial Misconduct: The Influence of Prosecutors." George Mason Legal Studies Research Paper No. LS 19-08. https://doi.org/10.2139/ssrn.3335138.

Philadelphia District Attorney's Office, February 19, 2019, "After One Year, the Reduction of Cash Bail in Philadelphia for Low-Level Offenses Found a Success," https://medium.com/philadelphiajustice/release-after-one-year-the-reductionof-cash-bail-in-philadelphia-for-low-leveloffenses-found-a-13448516a5bf.

Phillips, Mary. 2012. A Decade of Bail Research in New York City. New York City Criminal Justice Agency (New York). https://www.prisonpolicy.org/scans/DecadeB ailResearch12.pdf.

Picard, Sarah, Matt Watkins, Michael Rempel, and Ashmini Kerodal. 2019. Beyond the algorithm: Pretrial reform, risk assessment, and racial fairness. Center for Court Innovation (New York). https://www.courtinnovation.org/sites/defaul t/files/media/documents/201906/beyond the algorithm.pdf.

Prendergast, Michael L., Elizabeth A. Hall, Harry K. Wexler, Gerald Melnick, and Yan Cao. 2004. "Amity Prison-Based Therapeutic Community: 5-Year Outcomes." The Prison Journal 84 (1): 36-60. https://doi.org/10.1177/0032885503262454. 115th Congress. 2017. Pretrial Integrity and Safety Act. 
Pretrial Justice Institute. 2009. "The D.C. Pretrial Services Agency: Lessons From Five Decades of Innovation and Growth." Case Studies 2, no. 1. https://www.psa.gov/sites/default/files/PIIDCPSACaseStudy.pdf.

Pretrial Justice Institute. 2012. Using Technology to Enhance Pretrial Services: Current Applications and Future Possibilities.

http://thecrimereport.s3.amazonaws.com/2/8 5/0/1651/pji using technology to enhance p retrial_services.pdf.

Pretrial Justice Institute. 2018. Support Grows for Pretrial Justice Reform.

https://university.pretrial.org/HigherLogic/Sy stem/DownloadDocumentFile.ashx?Document FileKey=10a1c9d8-5a87-a895-e1f5b68ee06a4bf7\&forceDialog $=0$.

Rabuy, Bernadette, and Daniel Kopf. 2016. Detaining the poor: How money bail perpetuates an endless cycle of poverty and jail time. Prison Policy Initiative. https://www.prisonpolicy.org/reports/incom ejails.html.

Rehavi, M Marit, and Sonja B Starr. 2014. "Racial disparity in federal criminal sentences." Journal of Political Economy 122 (6): 13201354. https://doi.org/10.1086/677255.

Rosenbaum, David I, Nicole Hutsell, Alan J Tomkins, and Brian H Bornstein. 2011. "Court Date Reminder Postcards: A Benefit-Cost Analysis of Using Reminder Cards to Reduce Failure to Appear Rates." Judicature 95: 177.

Saloner, Brendan, Kalind Parish, Julie A. Ward, Grace DiLaura, and Sharon Dolovich. 2020. "COVID19 Cases and Deaths in Federal and State Prisons." JAMA. https://doi.org/10.1001/jama.2020.12528.

Sawyer, Wendy, and Peter Wagner. 2020. Mass incarceration: The whole pie 2020. Prison Policy Initiative (Northampton, MA). https://www.prisonpolicy.org/reports/pie202 0.html.

Schnacke, Timothy R, Michael R Jones, and Dorian M Wilderman. 2012. "Increasing courtappearance rates and other benefits of livecaller telephone court-date reminders: The Jefferson County, Colorado, FTA pilot project and resulting court date notification program." Court Review 48: 86.

Scott-Hayward, Christine S, and Sarah Ottone. 2018. "Punishing Poverty: California's Unconstitutional Bail System." Stanford Law Review 70: 167. https://www.stanfordlawreview.org/online/p unishing-poverty $/$.
Shalom, Alexander, Colette Tvedt, Joseph E. Krakora, and Diane DePietropaolo Price. 2016. The New Jersey Pretrial Justice Manual. National Association of Criminal Defense Lawyers (NACDL) and American Civil Liberties Union of New Jersey (Washington, DC). https://www.aclunj.org/files/3414/8708/6580/20161202 Pr etrial.pdf.

Sheriff's Justice Institute. 2016. Chicago Central Bond Court Report. https://www.chicagoreader.com/pdf/201610 26/Sheriff s-Justice-Institute-Central-BondCourt-Study-070616.pdf.

Sparks, Margaret Elizabeth. 2019. "Bailing on Bail: The Unconstitutionality of Fixed, Monetary Bail Systems and Their Continued Use throughout the United States." Georgia Law Review 52: 983. https://www.georgialawreview.org/article/76 66-bailing-on-bail-the-unconstitutionality-offixed-monetary-bail-systems-and-theircontinued-use-throughout-the-united-states.

Starr, Sonja B. 2014. "Evidence-based sentencing and the scientific rationalization of discrimination." Stanford Law Review 66: 803. https://www.stanfordlawreview.org/print/art icle/evidence-based-sentencing-and-thescientific-rationalization-of-discrimination/.

State Court Processing Statistics. 2009. Bureau of Justice Statistics.

Stevenson, Megan T. 2018a. "Assessing risk assessment in action." Minnesota Law Review 103: 303. https://doi.org/10.2139/ssrn.3016088.

Stevenson, Megan T. 2018b. "Distortion of Justice: How the Inability to Pay Bail Affects Case Outcomes." The Journal of Law, Economics, and Organization 34 (4): 511-542. https://doi.org/10.2139/ssrn.2777615.

Stevenson, Megan T., and Jennifer L. Doleac. 2019. "Algorithmic Risk Assessment in the Hands of Humans." Available at SSRN. https://doi.org/10.2139/ssrn.3489440.

Stevenson, Megan T., and Sandra G. Mayson. 2017. "Pretrial detention and bail." In Reforming Criminal Justice, edited by Erik Luna. Arizona State University: Academy for Justice.

Stevenson, Megan T., and Christopher Slobogin. 2018. "Algorithmic risk assessments and the doubleedged sword of youth." Washington University Law Review 96: 638-656. https://doi.org/10.1002/bsl.2384.

Tafoya, Sonya. 2013. Assessing the Impact of Bail on California's Jail Population. Public Policy Institute of California. https://www.ppic.org/content/pubs/report/R 613STR.pdf. 
Tafoya, Sonya. 2015. Pretrial detention and jail capacity in California. Public Policy Institute of California. https://www.ppic.org/publication/pretrialdetention-and-jail-capacity-in-california/.

Toman, Elisa L., Joshua C. Cochran, and John K. Cochran. 2018. "Jailhouse Blues? The Adverse Effects of Pretrial Detention for Prison Social Order." Criminal Justice and Behavior 45 (3): 316-339. https://doi.org/10.1177/0093854817753018.

Turner, Susan, Joan Petersilia, and Elizabeth Piper Deschenes. 1992. "Evaluating intensive supervision probation/parole (ISP) for drug offenders." Crime \& Delinquency 38 (4): 539556.

https://doi.org/10.1177/0011128792038004 $\underline{009}$.

Weaver, Vesla M, Andrew Papachristos, and Michael Zanger-Tishler. 2019. "The great decoupling: The disconnection between criminal offending and experience of arrest across two cohorts." The Russell Sage Foundation Journal of the Social Sciences 5 (1): 89-123. https://doi.org/10.7758/RSF.2019.5.1.05.
White, Wendy F. 2006. Court hearing call notification project. Criminal Justice Coordinating Council \& Flagstaff Justice Court (Coconino County, Arizona). www.coconino.az.gov/uploadedFiles/Criminal Justice Coordinating Council/ReportFTA.doc.

Yi, Youngmin, Kristin Turney, and Christopher Wildeman. 2017. "Mental health among jail and prison inmates." American Journal of Men's Health 11 (4): 900-909. https://doi.org/10.1177/1557988316681339.

Zeng, Jiaming, Berk Ustun, and Cynthia Rudin. 2017. "Interpretable classification models for recidivism prediction." Journal of the Royal Statistical Society Series A 180 (3): 689-722. https://doi.org/10.1111/rssa.12227.

Zoe Guttman is currently completing the Interdepartmental PhD Program for Neuroscience at the University of California, Los Angeles. Her research stands at the intersection of cognitive neuroscience, behavioral economics, and addiction to understand decision-making under conditions of risk and uncertainty. Zoe holds a BS in Neural Science and Psychology from New York University. She is also the cofounder and president of the Science Policy Group at UCLA.

Yuki Hebner is a student in the Gene Regulation, Epigenomics, and Transcriptomics PhD program at the University of California, Los Angeles. She studies chromatin remodeling during human corticogenesis to understand the epigenetic drivers of neuropsychiatric diseases. Previously, she studied histone biology at Wesleyan University. She is the internal vice president of the Science Policy Group at UCLA.

Kanon Mori is a pre-medical undergraduate student at the University of California, Los Angeles majoring in Molecular, Cellular, and Developmental Biology and minoring in Public Health. She currently conducts research to determine physician and health system factors that cause variation in the quality of care for patients with neurodegenerative diseases. She is most interested in the intersection of health and policy to advocate for a more equitable healthcare system.

Jonathan Balk is a recent graduate of the University of California, Los Angeles and is currently a research assistant at the RAND Corporation in Santa Monica, California. His work has contributed to a NASA additive manufacturing in space program. Currently, he is working on space policy and space domain issues supporting a variety of government organizations. He has additional interests in social justice and education policy. 